\title{
Exploring Consumers' Preferred Purchase Location for Fresh Fruits
}

\author{
Juliano Martins Ramalho Marques ${ }^{1}$, Ariana P. Torres ${ }^{2,3}$, \\ Bridget K. Behe ${ }^{4}$, Petrus Langenhoven ${ }^{5}$, and \\ Luiz Henrique de Barros Vilas Boas ${ }^{1}$
}

Additional InDEX words. attitudes, attributes, chain stores, fresh fruits, local, market channel

Summary. Before consumers choose what and how much fruit to buy, they first decide where to buy it. To address the choices of stores for fresh fruits, this study investigated the influence of market attributes and customers' attitudes toward their purchasing decisions. Data from a web-based survey of 1658 U.S. consumers were used to conduct multinomial logit regression to investigate the factors guiding their choices regarding four types of stores: chain, independent, club/warehouse, and direct-to-consumer. We found attitudinal scales and market attributes have different effects on the choice of marketplace for fresh fruits. Driven by price and convenience, most consumers prefer chain stores when buying fresh fruits, whereas those same factors deter them from choosing independent and ethnic stores for fresh fruits. The supply of local fruits, friendly atmosphere, and access to desirable fresh fruits positively influenced consumers to purchase fruits at local markets. Our findings can provide insight regarding food retailers and farmers targeting fresh fruit consumers. For example, our findings highlight the importance of providing a friendly atmosphere and outstanding customer service to positively influence purchasing behavior.

A mericans are consuming more fresh fruits than ever [Bentley, 2017; U.S. Department of Agriculture-Economic Research Service (USDA-ERS), 2018]. To illustrate, the U.S. per capita consumption of fresh fruits grew by 12\% between 2010 and 2018 (Kenner, 2020). Increasing fresh fruit consumption is likely driven by health benefits, as well as dietary guidelines promoted by federal and local governments (Schauder et al., 2019). For instance, the fact that consumption of fresh whole fruits has been reported to extend life expectancy and reduce disease risk is likely to encourage consumption (Lusk and McCluskey, 2018; World Health Organization, 2001).

The rising demand for fresh fruits has impacted revenues and profitability of food retailers, including grocery stores. In 2016, produce departments of grocery stores generated nearly $\$ 48$ billion in sales, and $\approx 32 \%$ of that was attributed to fresh fruits, making it one of the most lucrative fresh food categories (USDAERS, 2018). Similarly, direct-to-consumer (DTC) farm sales increased more than 170\% between 2008 and 2015; this growth was primarily driven by fresh produce sales (U.S. Department of Agriculture, National Agricultural Statistics
Service, 2016), including fresh fruits. This sales increase can be explained by increasing purchasing power, customer motivation to participate in local food systems, and the promotion and growth of local outlets (Ferdinand et al., 2017; Figueroa-Rodríguez et al., 2019). The DTC marketplaces include communitysupported agriculture (CSA), farmer's markets, on-farm stores, and roadside stands.

To respond to the rising demand for fresh fruits, farmers and food retailers have increased their product mix and product form (e.g., ready-toeat), and they have adopted marketing strategies to differentiate themselves from other retailers (Brunori et al., 2016). These differentiation strategies include using food labels that convey food attributes, delivery options, prepackaged fresh products, and other "out-of-the-box" foods aimed at increasing the market share and consumer experience for fresh produce. Yet, markets are rarely homogenous, and the proliferation of food labels seems to be generating skepticism and changing demands among consumers (Sirieix et al., 2013; Vega-Zamora et al., 2018). Most of these changes in fresh fruit consumption have been linked to consumers' attitudes toward health benefits and place of purchase (Schoenbachler and Gordon, 2002; Uyttendaele et al., 2014). Acquiring a better understanding of what consumers want, how their preferences change, and how to immediately address these changes, is not only a success factor for farmers and food retailers but a survival one when abrupt market changes occur (Freire and Rudkin, 2019).

The high levels of dynamism and competition present in fresh produce markets have forced food retailers to be more proactive in identifying consumer preferences and their decisionmaking process (Barrena et al., 2017). To gain a better understanding of the changes in consumer demand, several researchers have investigated what drives consumers to purchase and consume fresh fruits. Researchers have reported fresh fruit purchases can be driven by product attributes and consumer attitudes (Bir et al., 2019; Canova et al., 2020; Lancaster and Torres, 2019; Massaglia et al., 2019; Torres et al., 2020; Witzling and Shaw, 2019). For example, consumers are increasing their knowledge of the benefits of eating fresh fruits (Canova et al., 2020) and valuing the experience of eating fresh fruits (Torres et al., 2020). Massaglia et al. (2019) found that when choosing fresh fruits, consumers were mainly influenced by intrinsic and sensory product attributes such as origin, freshness, and seasonality. Mugera et al. (2017) reported that consumers' preferences for nonsensory fresh fruits attributes include food safety and nutritional content. Torres et al. (2020) reported the search (size and lack of bruises), experience (flavor), and credence (local and pesticide-free) attributes favored by fresh fruit consumers.

Researchers also found that attitudes have a key role in consumer decision-making (Roininen et al., 2001; Verneau et al., 2016). Woo and Kim (2019) found a relationship between attitudes toward purchasing green food products and buying intentions. Individuals wanting to reduce the environmental damage caused by agriculture tend to prefer purchasing organic foods. Torres et al. (2020) identified different consumer attitudes guiding melon ( $\mathrm{Cucu}$ mis melo) consumption. For example, consumers who valued health and a 
variety of fresh fruits in their diets were also those consuming fruits most often. Four attitudinal scales have been extensively used in the literature to understand consumer food choices: General Health Interest (GHI), Craving Sweet Food (CSF), Food Pleasure (FP), and Variety Seeking in Foods (VSF). The GHI scale indicates consumer preferences for attributes related to health (Roininen et al., 2001). Consumers with higher ratings on the CSF scale tend to perceive sweetness as a desirable fresh fruit attribute (Saba et al., 2019). The FP scale has been associated with better nutritional status or larger food intake (Davidenko et al., 2015). Finally, the VSF scale has been correlated with an increase in fruit consumption (Nakagawa and Kotani, 2017; van Trijp and Steenkamp, 1991).

Received for publication 20 Apr. 2021. Accepted for publication 24 Jun. 2021.

Published online 11 August 2021.

${ }^{1}$ Department of Horticulture and Landscape Architecture, Purdue University; Department of Adminis tration and Economic, Lavras University, Cx Postal 37 Campus Universitario 37200000 Lavras, Minas Gerais, Brazil

${ }^{2}$ Department of Horticulture and Landscape Architecture, Purdue University, 625 Agriculture Mall Drive, West Lafayette, IN 47907

${ }^{3}$ Department of Agricultural Economics, Purdue University, 625 Agriculture Mall Drive, West Lafayette, IN 47907

${ }^{4}$ Department of Horticulture, Michigan State University, 1066 Bogue Street, East Lansing, MI 48824

${ }^{5}$ Department of Horticulture and Landscape Architecture, Purdue University, 625 Agriculture Mall Drive, West Lafayette, IN 47907

This material is based on work supported by a U.S. Department of Agriculture (USDA), National Institute of Food and Agriculture (NIFA) Small and Mid-Size Farms program (award no. 2017-68006-26342, and we appreciate the USDA for the grant provided to support this research effort. The USDA is an equal opportunity employer and service provider. Any opinions, findings, conclusions, or recommendations expressed in this publication are those of the author(s) and do not necessarily reflect the views of the USDA. We appreciate the USDA for the grant provided to support this research effort. We thank the Coordination for the Improvement of Higher Education Personnel, Brazil (Capes) under the Capes-PrInt Program (process no. 88887.364642/ 2019-00 and no. 88887.369999/2019-00) for supporting with researcher salary.

J.M.R.M. is a Visiting Researcher.

A.P.T. is an Assistant Professor.

B.K.B. is a Professor.

P.L. is a Horticulture/Hydroponic Crop Specialist.

A.P.T. is the corresponding author. E-mail: torres2@purdue.edu.

This is an open access article distributed under the CC BY-NC-ND license (https://creativecommons. org/licenses/by-nc-nd/4.0/).

https://doi.org/10.21273/HORTTECH04865-21
Most research has focused on the product attributes and consumer attitudes when purchasing fresh fruits; however, more recently, researchers have linked the selection of an outlet as the first step in the consumer's purchase decision-making for fresh fruits. Gindi et al. (2018) proposed that fresh fruit purchases follow a hierarchical process whereby the selection of the marketplace is the first decision that leads to determining the purchasing behavior. Therefore, we expect that before consumers choose what and how much fruit to buy, they first decide where to make the purchase. We also expect that distinct marketplace characteristics and consumer attitudes may differently drive the decision to choose a primary marketplace for fresh fruits.

This study takes a step back from the product attribute literature to understand how marketplace attributes and consumers' attitudes influence the choice of primary market for fresh fruit purchases. Although consumer preferences for fresh fruits are well-documented in the literature, what guides them to choose among a wide variety of marketplaces is not sufficiently detailed (Arsil and Li, 2018; Gindi et al., 2018; Kumar and Smith, 2018; Massaglia et al., 2019). Only a few studies have investigated the drivers and barriers faced by shoppers at specific food stores (Lenk et al., 2018), and most of those studies have focused on consumers' choices of DTC markets (Arsil and Li, 2018).

The goal of this study was to investigate the factors guiding the choice of marketplaces for fresh fruit purchases. The four widely used attitudinal scales (i.e., GHI, CSF, FP, and VSF) were studied to predict the consumer choice of marketplace. By aligning the consumer attitudinal scales predicting market choice and marketplace attributes, this study shed light on the marketplace choices among fresh fruit consumers. We also investigated what demographic characteristics and purchasing behaviors influence consumers to purchase fresh fruits at different market outlets. The combination of intrinsic and extrinsic consumer characteristics predicting the marketplace choice comprised the unique approach of this research. Using data from an online survey, we conducted an attitudinal assessment of fresh fruit consumers at four market categories: chain stores, club stores or warehouses, independent grocery stores, and DTC markets. Chain stores included large traditional grocery stores such as Walmart (Bentonville, AR) and Meijer (Grand Rapids, MI). Club stores included wholesale warehouses selling products in bulk quantities, such as Costco (Issaquah, WA) and Sam's Club (Bentonville, AR). Independent grocery stores included independent, ethnic, and natural grocery stores. Finally, DTC markets included farmer's markets, roadside stands, at the farm, and CSA. To the best of our knowledge, this is the first study to use attitudinal scales and marketplace attributes to understand what drives consumers to choose their primary marketplace for fresh fruits.

\section{Data and methodology}

Data Description. Data from this study were obtained from a webbased survey of fresh fruit purchasers in the United States. The questionnaire was approved by the Institutional Review Board for compliance with ethical standards for human subjects (number 1807020586). Questionnaire development was guided by a review of the literature and interviews with researchers and extension personnel working in food systems, consumers, and fresh fruit retailers. Similar to the work by Torres et al. (2020), the survey was distributed by LightSpeed GMI (Bridgewater, NJ) during late Summer and early Fall 2018 to potential respondents who were part of their proprietary opt-in panel of U.S. households.

We recruited respondents who were at least 18 years old and purchased fresh fruits at least once during the 12 weeks before data collection, a timeline that overlaps with the highest consumption of fresh fruits (Curtis et al., 2019). This timeline was also chosen based on the abundance of fresh fruits available in the market channels (Chatziprodromidou et al., 2018). The sample of surveyed participants was recruited to be representative of the U.S. population based on age, sex, and pretax income based on the 2017 American Community Survey (ACS). For example, the proportion of 18- to 34-year-old individuals in our sample was $30.4 \%$ compared with $30.1 \%$ in the 2017 ACS. Similar comparison rates were achieved for respondents between 35 and 54 years 
of age (32.8\% vs. $33.1 \%), 55$ and 64 years of age ( $16.0 \%$ vs. $16.7 \%)$, and those 65 years and older $(20.8 \%$ vs. $20.1 \%)$. The proportion of women in our sample was $47 \%$ compared with $51 \%$ in the 2017 ACS. Respondents who earned less than $\$ 50,000$ in 2017 represented $44.8 \%$ of our sample (compared with $42.1 \%$ in the ACS). Respondents with household income ranging from $\$ 50,000$ to $\$ 150,000$ comprised $44.8 \%$ of our sample (vs. $44.7 \%$ in the ACS). Finally, those reporting household income more than $\$ 150,000$ comprised $10.37 \%$ of our sample (vs. $13.2 \%$ in the ACS).

The sample of this study comprised 1658 respondents after eliminating respondents for a variety of reasons (i.e., failure to pass attention checks, identical responses in a section, and incomplete responses). To gain a better understanding of the market attributes guiding consumers, we categorized respondents based on their primary market for fresh fruits based on four main groups of outlets: chain stores [66\% $(\mathrm{N}=1095)]$, club/ warehouse stores $[5 \%(\mathrm{~N}=85)]$, independent grocery stores $[18 \%(\mathrm{~N}=$ $304)]$, and DTC markets [ $11 \%(\mathrm{~N}=$ 174)].

We asked respondents about the importance they placed on the following market attributes when purchasing fresh fruits at their selected primary marketplace: market availability, availability of desirable fresh fruits, prices, market proximity, fresh fruits selection, friendliness of the market, convenience, supply of locally grown fruits, supply of organic fruits, fruits sourced from family-owned farms, access to seasonal fruits, and variety of fresh fruits. Fresh fruit selection was used to capture the different types of fresh fruit available at a marketplace, whereas fresh fruit diversity was used to capture the variety of similar and different fruit types. Market attributes were measured using a scale ranging from 0 to $100(0=$ not at all important; $100=$ extremely important). Respondents were asked to slide bars to select the level of importance placed on the aforementioned market attributes. Attitudes were measured by attitudinal scales, including the GHI, FP, CSF, and VSF scales. To uncover the most salient attitudinal factors influencing market choice, we conducted a principal component analysis of the GHI, FP, CSF, and VSF scales using the MEANS, FACTOR, and CORR procedures of SAS statistical software (version 9.4 for Windows; SAS Institute, Cary, NC).

Table 1 describes the dependent and independent variables used during the study. The questionnaire included questions regarding purchasing and consumption of fresh fruits, including the number of miles traveled to their primary marketplace, monthly expenditures, and the person responsible for purchasing in the household. Using region categorization from the Bureau of Labor Statistics, Table 1 shows the regional groups used in the study (Northeast, South, Midwest, and West).

We considered the choice of market channel as a treatment effect for means comparisons and computed multiple comparisons among the variable means using an analysis of variance (ANOVA) model and Tukey's honestly significant difference method at the $10 \%$ significance level. Because of the unordered and discrete nature of the marketplace categories, a robust multinomial logit regression was performed to understand what influences the choice of primary marketplace among fresh fruit consumers. The robust multinomial logit model describes the consumers' choices when faced with a variety of marketplaces; however, the marketplaces are likely to be highly differentiated by attitudinal scales and market attributes.

We hypothesized that the GHI, FP, CSF, and VSF scale scores would impact the choice of marketplace differently. We expected that consumers with high ratings on the GHI and FP scales would be more likely to purchase fresh fruits at DTC and independent stores, whereas those with high ratings on the CSF and VSF scales would favor purchasing fresh fruits at club/warehouse and chain stores. We also hypothesized that market attributes related to seasonality, organic fruit offerings, friendliness of the store atmosphere, and availability of local products drive consumers to purchase fresh fruit at DTCs and independent/ethnic stores, whereas price, fresh fruit selection, convenience, and fruit diversity increase the likelihood to purchase at chain and club stores.
The multinomial logit followed a logistic distribution:

$$
\begin{aligned}
\operatorname{Prob}[\text { market }=j] & =\frac{e^{X_{i}^{\prime} \beta_{j}}}{1+\sum_{m=1}^{m-1} e^{X_{i}^{\prime} \beta_{k}}} ; j \\
& =1,2, \ldots ., m-1 ; i \\
& =1,2, \ldots, n
\end{aligned}
$$

where $\operatorname{Prob}[$ market $=j]$ denotes the probability that a respondent will choose the $j$ th marketplace, $X_{i}$ is a vector of observables including attitudinal scales and market characteristics, and $\beta_{j}$ is a vector of unknown parameters to be estimated for the $m-1$ market choices. The marginal effects, which are partial derivatives of probabilities regarding the set of independent variables, were calculated from multinomial logit results using the following equation:

$$
\begin{aligned}
\frac{\partial P_{j}}{\partial X_{i}} & =P_{j}\left(\beta_{j i}-\sum_{m=1}^{m-1} P_{j i} \beta_{j i}\right) ; j \\
& =1,2, \ldots, m ; i=1,2, \ldots, n
\end{aligned}
$$

where $\frac{\partial P_{j}}{\partial X_{i}}$ represents the change in the probability of a respondent choosing a marketplace $j$ with regard to a oneunit change in the $i$ th explanatory variable, $X_{i}$. The derivative was evaluated at the overall sample mean of $X_{i}$, where the effects are observed as $\beta_{j i}$ percentage changes of the probability. Because an increase in the probability of choosing a marketplace must be offset by a decrease in the probability of choosing another marketplace, the marginal probabilities of the independent variables sum to zero.

Analyses were conducted using Stata statistical software (release 16; StataCorp, College Station, TX). Variables in the vector $X$ were set at mean levels to predict the probability of each independent variable impacting the dependent variable. A correlation analysis showed multicollinearity between the marketplace attributes "fruits from family-owned farms," "offering local fruits," and "offering organic fruits," suggesting that respondents may have a singular understanding of those marketplace attributes. Therefore, we omitted the "family-owned farms" variable.

\section{Results and discussion}

Summary statistics. Table 2 describes the explanatory variables and mean differences for all variables by marketplace categories. Almost 
Table 1. Categories and descriptions of dependent variable (market) and independent variables used to investigate the factors influencing marketplace choice for fresh fruits among U.S. consumers.

\begin{tabular}{lc}
\hline Variable & Description \\
\hline Dependent variable & \\
\hline Market $^{\mathrm{z}}$ & $\begin{array}{c}1=\text { respondent buys most fruits at a big chain store; } 2=\text { respondent buys most } \\
\text { fruits at a warehouse or club store; } 3=\text { respondent buys most fruits at an } \\
\text { independent grocery or ethnic store; } 4=\text { respondent buys most fruits at direct- } \\
\text { to-consumer markets }\end{array}$ \\
\hline
\end{tabular}

Explanatory variables

\begin{tabular}{|c|c|}
\hline Demographic characteristics & \\
\hline Female & $1=$ respondent is female; $0=$ otherwise \\
\hline Single & $1=$ respondent is single; $0=$ otherwise \\
\hline Income & Per capita household income \\
\hline Age & Respondent age \\
\hline Number of children in household & Number of children in household \\
\hline Lives in Midwest & $\begin{array}{c}\mathrm{l}=\text { respondent lives in Illinois, Indiana, Iowa, Kansas, Michigan, Minnesota, } \\
\text { Missouri, Nebraska, North Dakota, Ohio, South Dakota, Wisconsin }\end{array}$ \\
\hline Lives in the West & $\begin{array}{l}\mathrm{l}=\text { respondent lives in Alaska, Arizona, California, Colorado, Hawaii, } \\
\text { Idaho, Montana, Nevada, New Mexico, Oregon, Utah, Washington, } \\
\text { Wyoming }\end{array}$ \\
\hline Lives in the Northeast & $\begin{array}{l}\mathrm{l}=\text { respondent lives in Connecticut, Maine, Massachusetts, New } \\
\text { Hampshire, New Jersey, New York, Pennsylvania, Rhode Island, Vermont }\end{array}$ \\
\hline Asian & $1=$ respondent is Asian; $0=$ otherwise \\
\hline Black & $1=$ respondent is African American; $0=$ otherwise \\
\hline White & $1=$ respondent is White $/$ Caucasian; $0=$ otherwise \\
\hline Hispanic & $1=$ respondent is Hispanic $; 0=$ otherwise \\
\hline
\end{tabular}

Purchase variables

Responsible for purchasing $\mathrm{FF}^{\mathrm{y}}$

Miles traveled

Monthly amount spent on FF

$\mathrm{l}=$ respondent is responsible for buying fresh fruits; $0=$ otherwise

Miles traveled to the primary outlet when buying fresh fruits

Monthly expenditures on fresh fruits

Market attributes ${ }^{\mathrm{x}}$

Only place offering desirable FF

Market price

Only place offering the fresh fruit respondent wants

Closeness to consumers home

Respondent consideration for the market prices for fresh fruits

Market availability

Closest distance to respondent's home

FF selection

No other outlet in the respondent's area

Friendliness of atmosphere

Respondent's consideration of the fresh fruit selection

Convenience

Respondent's consideration of the marketplace friendliness

Offering local fruits

Respondent's consideration of the marketplace convenience

Offering organic fruits

Respondent's consideration of the locally grown fresh fruit offered

Seasonal fresh fruits

Respondent's consideration of the organic fresh fruit offered

Fresh fruit diversity

Respondent's consideration of the seasonal fruit offered

Respondent's consideration of the marketplace fresh fruit diversity

Attitudinal scales

General health interest

Cravings for sweet food

Food pleasure

Variety seeking in food
Respondent's general health interest scale

Respondent's cravings for sweet food scale

Respondent's food pleasure scale

Respondent's variety seeking in food scale

${ }^{{ }^{z} \text { Chain stores included large traditional grocery stores such as Walmart (Bentonville, AR) and Meijer (Grand Rapids, MI). Club stores included wholesale warehouses }}$ selling products in bulk quantities, such as Costco (Issaquah, WA) and Sam's Club (Bentonville, AR). Independent grocery stores included independent, ethnic, and natural grocery stores. Direct-to-consumer markets included farmer's markets, roadside stands, at the farm, and community-supported agriculture.

${ }^{y} \mathrm{FF}=$ fresh fruits.

${ }^{\mathrm{x}}$ Market attributes vary from 0 to 100 on the importance scale $(0=$ not at all important; $100=$ extremely important $)$. 


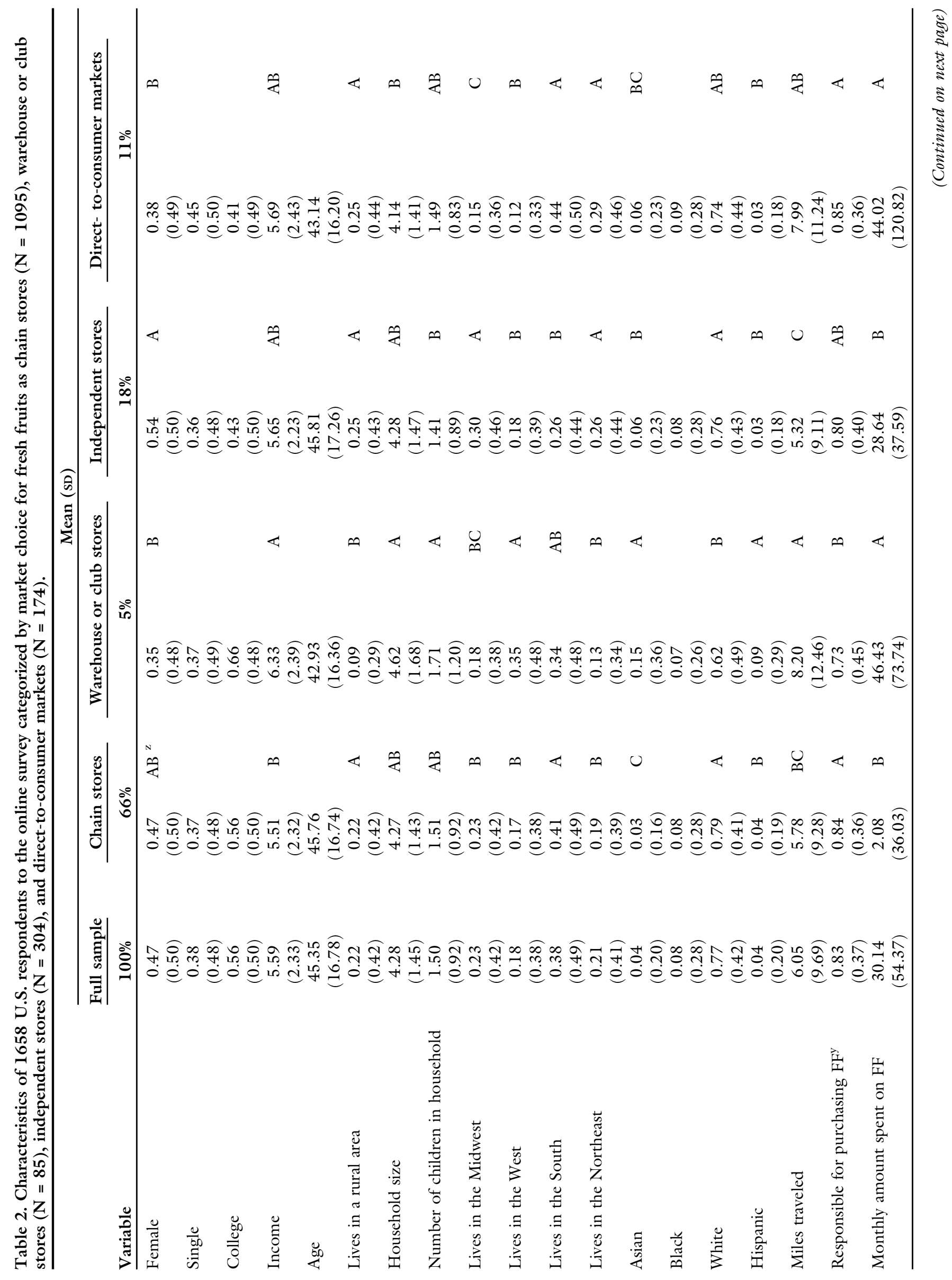




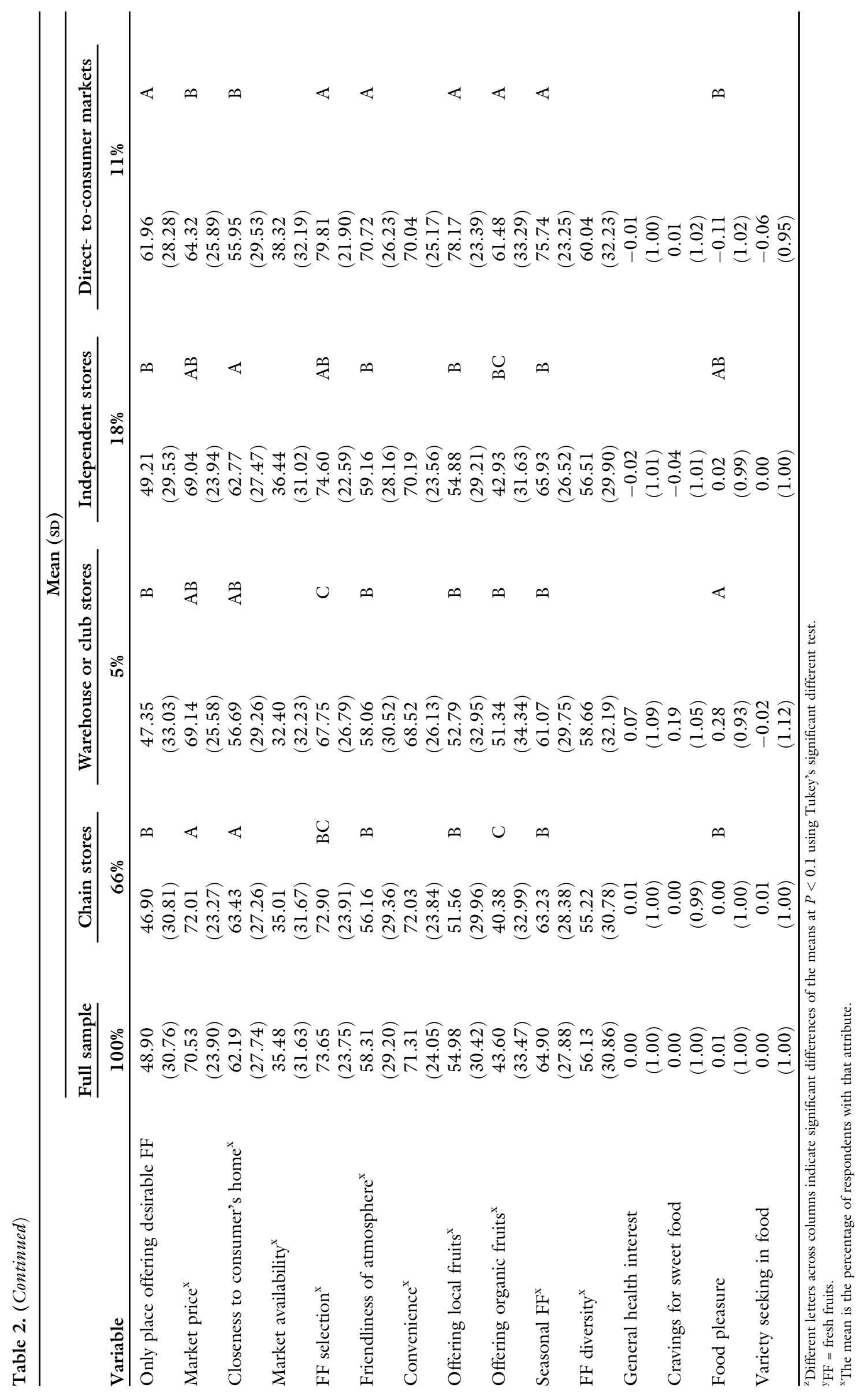


half of the sample was female, and they mostly chose independent stores (54\%) when purchasing fresh fruits instead of DTC and club stores $(P<$ 0.1 ). Respondents with more children and bigger households seemed to prefer purchasing fresh fruits at club stores instead of independent stores and DTC markets $(P<0.1)$. These results suggest that family-size packages of fruits in club stores are preferred by larger families, which may provide sufficient servings for family members and reduce shopping trips.

More than half of the respondents $(56 \%)$ had a college education or a higher degree, but there were no differences in educational attainment among categories. Higher-income households reported purchasing most fresh fruits at club stores rather than chain stores $(P<0.1)$. This outcome suggested that club store managers may benefit from supplying a wider diversity of fresh fruit because highincome individuals tend to prefer differentiated and whole foods and are more likely to pay for them (Pollack, 2001).

Less than one-quarter of respondents were located in rural areas $(22 \%)$, and club stores were the least common choice for buying fresh fruits among rural residents $(P<0.1)$. Consumers living in different regions preferred different marketplaces when buying fresh fruits, perhaps partly because of access to these markets. Consumers in the South reported buying most fresh fruits at DTC and chain stores instead of club and independent stores $(P<0.1)$. The fact that consumers in the South were more likely to buy fresh fruits at local markets may be driven by the longer seasonality and availability of fresh produce in the southern United States because of the warmer climate compared with more northern regions. Even with the number of farmer's markets increasing in the West (Christensen et al., 2017), respondents in the West chose mainly club stores instead of other marketplaces $(P<0.1)$. Respondents in the Northeast preferred to buy fresh fruits at DTC and independent stores instead of other marketplaces $(P<0.1)$. Finally, respondents located in the Midwest chose independent stores for fresh fruits purchases instead of other marketplaces $(P<0.1)$.

More than three-quarters of the respondents were Caucasian $(77 \%)$ and preferred buying fresh fruits at chain stores and independent stores instead of club stores $(P<0.1)$. Asian and Hispanic individuals reported similar marketplace preferences for fresh fruits and chose club stores instead of other marketplaces $(P<0.1)$. African American individuals showed no significant differences regarding the choice of marketplace for fresh fruits.

Respondents reported spending an average of $\$ 30.14$ per month on fresh fruits. The fact that the survey was delivered between late summer and early fall, when the availability and purchasing of fruits tend to be higher (Curtis et al., 2019), should be considered when interpreting the monthly expenditures on fresh fruits. Consumers purchasing fresh fruits at DTC marketplaces spent more every month compared with those purchasing at chain and independent stores $(P<0.1)$. These results might be influenced by the greater availability and higher prices of fresh fruits at farmer's markets compared with those at other markets (Salisbury et al., 2018).

Consistent with the results of Bir et al. (2019), most survey respondents $(83 \%)$ reported being in charge of purchasing fresh fruits for their household. Those in charge of purchasing fresh fruits reported a higher preference for chain stores and DTC marketplaces than for club stores $(P<0.1)$. The one-stop shop characteristic of chain stores and additional amenities of farmer's markets (i.e., food and music events) may be driving these individuals to prefer these marketplaces. On average, respondents traveled 6.1 miles to purchase fresh fruits. They reported traveling farther distances to club stores and DTC than to chain and independent stores $(P<0.1)$. These results suggested that club stores and DTC managers might be able to expand the range of advertising campaigns to draw customers from farther niche markets.

We asked respondents about the importance they placed on 11 market attributes (Table 2). Overall, the three most valued attributes were fresh fruit selection $(74 \%)$, market convenience $(71 \%)$, and price $(70 \%)$. Less important attributes were seasonal fruits $(65 \%)$, closeness to home $(62 \%)$, friendliness of atmosphere (58\%), diversity of fresh fruits (56\%), offering local fruits $(55 \%)$, the only place offering fresh fruits $(49 \%)$, access to organic fruits (44\%), and market availability in the respondent's area (35\%). Access to local, organic, seasonal, and selected fresh fruits as well as friendly atmosphere were more important to those purchasing at DTC markets $(P<0.1)$. As expected, price was more important to those buying most fresh fruits at chain stores compared with DTC buyers $(P<0.1)$. Market closeness was important to buyers purchasing most fresh fruits at chain and independent stores compared to club and DTC markets $(P<0.1)$.

Four attitudinal scales were used to assess how consumer attitudes influence the choice of market for fresh fruits: GHI, CSF, FP, and VSF. Results of the GHI scale principal component analysis showed that all eight questions had loadings $>0.59$, with adequate fit statistics [measure of sampling adequacy $(\mathrm{MSA})=0.835$; standardized Cronbach's $\alpha=0.821$ ] (Hair et al., 1998). The variables considered as one component explained $45 \%$ of the variance. The means ranged between 3.0 and 3.9 on a 5 point Likert scale. The moderate means indicated that participants had a liking for healthy diets.

For the CSF scale principal component analysis, three of the six items of the scale that had loading $>0.81$, adequate fit statistics $(\mathrm{MSA}=0.700)$, and explained $70.7 \%$ of the variance were kept. The mean of the items varied between 3.4 to 3.7 on a 5 -point Likert scale. This result indicated that the sample had cravings for sweet food slightly beyond the CSF scale midpoint. The other three items were omitted because of low loading coefficients.

Considering the FP scale, three items were kept from the principal component analysis and three others were omitted because of low scores for the factor pattern. The remaining items explained $60.7 \%$ of the variance, with adequate fit statistics (MSA = $0.665)$. The items had loading $>0.77$. The mean scores for each item varied from 3.6 to 4.0 on a 5 -point Likert 
Table 3. Marginal effects results from the multinomial logit regression used to investigate the factors influencing the marketplace choices for fresh fruits among U.S. consumers.

\begin{tabular}{|c|c|c|c|c|c|c|c|c|}
\hline \multirow{2}{*}{$\frac{\text { Variable }}{\text { Female }}$} & \multicolumn{2}{|c|}{$\begin{array}{l}\text { Chain } \\
\text { stores }\end{array}$} & \multicolumn{2}{|c|}{ Warehouses or Club stores } & \multicolumn{2}{|c|}{$\begin{array}{c}\text { Independent } \\
\text { stores }\end{array}$} & \multicolumn{2}{|c|}{ Direct-to-consumer markets } \\
\hline & -4.18 & $*$ & -0.5 & & 6.2 & $* * *$ & -1.52 & \\
\hline Age & 0.07 & & 0 & & -0.06 & & -0.01 & \\
\hline College & 1.09 & & 0.09 & & -1.75 & & 0.57 & \\
\hline Income & 0 & & 0 & $* *$ & 0 & & 0 & \\
\hline Number of children in household & 2.35 & & 0.15 & & -3.14 & $*$ & 0.64 & \\
\hline Lives in the Midwest & 3.38 & & 1.69 & & -1.79 & & -3.28 & $* *$ \\
\hline Lives in the West & 5.12 & & 3.33 & $* *$ & -4.39 & & -4.06 & $* *$ \\
\hline Lives in the South & 11.13 & $* * *$ & 1.73 & & -12.43 & $* * *$ & -0.43 & \\
\hline Asian & -17.9 & $* * *$ & 4.71 & $* * *$ & 8.74 & $*$ & 4.45 & $* *$ \\
\hline Black & -2.36 & & -0.39 & & 3.53 & & -0.78 & \\
\hline Monthly amount spent on FF & -0.03 & & 0.01 & $* *$ & 0.01 & & 0.01 & \\
\hline Only place offering desirable FF & -8.47 & $*$ & -0.31 & & 1.45 & & 7.33 & $* * *$ \\
\hline Market price & 11.56 & $* *$ & 1.52 & & -8.22 & $*$ & -4.86 & $* *$ \\
\hline Closeness to consumer's home & 6.5 & & -2.77 & & 4.55 & & -8.28 & $* * *$ \\
\hline Market availability & 3.32 & & -2.82 & & 2.51 & & -3 & $*$ \\
\hline FF selection & 5.17 & & -5.16 & $* *$ & 4.87 & & -4.89 & $*$ \\
\hline Friendliness of atmosphere & -17.51 & $* * *$ & 2.61 & & 7.69 & & 7.21 & $* *$ \\
\hline Convenience & 17.7 & $* *$ & -0.87 & & -12.85 & $* *$ & -3.97 & \\
\hline Offering local fruits & -15.74 & $* *$ & -1.17 & & -1.82 & & 18.73 & $* * *$ \\
\hline Offering organic fruits & -5.25 & & 4.65 & $* *$ & -1.73 & & 2.33 & \\
\hline Seasonal FF & -1.55 & & -3.3 & & 5.23 & & -0.37 & \\
\hline FF diversity & 5 & & 2.94 & & -2.65 & & -5.29 & $* *$ \\
\hline
\end{tabular}

${ }^{{ }^{2} P}>$ chi-square $=0.00$; pseudo $R^{2}=0.13$; marginal effects are expressed in percentage points.

${ }^{\mathrm{y}} \mathrm{FF}=$ fresh fruits.

$* P<0.1, * * P<0.05, * * * P<0.01$.

scale, indicating that this sample of fresh fruit buyers considered the food pleasure.

Of the eight items of the VSF scale questionnaire, six were retained after the principal component analysis. The retained items explained $65.5 \%$ of the variance, with adequate fit statistics $(\mathrm{MSA}=0.900)$. Of the two not retained, one was omitted because of low loading $(0.4414)$ and the other was omitted because of the very low final communality estimate $(0.1948)$. The mean of the remaining items ranged from 3.4 to 3.7 on a 5-point Likert scale, which means buyers are interested in prioritizing the variety in food. The principal component analyses of the scales were generated using the MEANS, FACTOR $($ METHOD $=p$ and PRIORS $=1)$, and CORR procedures of SAS software (SAS for Windows version 9.4).
According to the ANOVA results, the GHI, CSF, and VSF scales showed no significant difference among the type of market chosen for fresh fruits $(P>0.1)$. Those purchasing at club and independent stores had higher ratings on the FP scale compared with those purchasing fresh fruits at chain stores and DTC markets $(P<0.1)$. These results suggest that managers of club and independent stores should highlight advertisements using a combination of visual (sight), tactile (touch), and olfactory (smell) cues when promoting fresh fruits, which could evoke high pleasure perceptions (Petit et al., 2016).

Regression results. Table 3 provides the marginal effects of the multinomial logit regression. The CSF and VSF scales were the only attitudinal scales influencing shoppers' choices of marketplace for fresh fruits. Shoppers with high ratings on the CSF scale were more likely to choose club stores $[1 \%(P<0.05)]$ and DTC markets $[1 \%(P<0.1)]$ for fresh fruits. Because sweetness is an experience attribute validated after consumption, these results suggest the importance of signaling the sweetness of fresh fruits through creative labels and logos, as well as through social media marketing campaigns. It also seems that providing samples of sweet fresh fruits for consumers to taste may motivate consumers to buy fruits. This is particularly true because most purchase decision-making is made at the place of purchase (Nair and Shams, 2020). Shoppers with high ratings on the VSF scale were less likely to shop for fresh fruits at club stores $[1 \%(P<0.05)]$. Consistent 
with the results of Ailawadi et al. (2018), our results suggest that having access to bundles containing a diverse selection of fruit types may entice consumers seeking a variety of fresh fruits at club/warehouse stores.

The only market attribute driving customers to choose club/warehouse stores was access to organic fruits [5\% $(P<0.05)]$, and fruit selection $[5 \%$ $(P<0.05)]$ was a major barrier to purchasing fruits at these stores. Our results were consistent with those of Ailawadi et al. (2018) and Chen and Saghaian (2017), who suggested the importance of expanding the offering of organic fruits at club stores to attract customers. Consistent with the results of Volpe et al. (2017), residents of rural areas were $2 \%$ less likely to choose club stores $(P<0.1)$ as their main market for fresh fruit purchases. One explanation may be that distance and additional membership requirements can discourage rural residents to shop at club stores (Ailawadi et al., 2018; Lim et al., 2020).

Market attributes driving fruit buyers to purchase at DTC markets were offering local fruits $[19 \%$ $(P<0.01)]$, the only place offering desirable fresh fruits $[7 \%(P<0.05)]$, and friendly atmosphere $[7 \%$ $(P<0.05)]$. These findings were consistent with those of previous studies reporting the drivers to purchase local produce (Arsil and $\mathrm{Li}$, 2018; Low et al., 2020). Ritter (2017) reported that local customers tend to be highly satisfied with the farmer's market availability of fresh produce and friendliness of the market atmosphere. Syeda (2019) described customers who favored the possibility of sharing recipes with farmer's market vendors, which is likely to build trust relationships between customers and farmers (Torres et al., 2016). In contrast, closeness to home $[8 \%(P<0.01)]$, market prices $[5 \%(P<0.05)]$, fresh fruit diversity $[5 \%(P<0.05)]$, and fresh fruit selection $[5 \%(P<0.1)]$ were major barriers to purchasing fresh fruits at DTC markets. Gumirakiza et al., (2014) also noted that distance was a major factor discouraging consumers from shopping at local markets. Regarding fruit diversity and selection, our results may be explained by the fact that farmer's markets and other local stores tend to have a short length of market season and high fruit seasonality, which may drive consumers to purchase from multiple locations to satisfy their produce needs throughout the year (Printezis and Grebitus, 2018).

Demographic characteristics influencing the likelihood to choose DTC markets included marital status, household size, location, and ethnicity. The fact that married individuals $[2 \%(P<0.05)]$ and those with larger households $[1 \%(P<0.1)]$ were less likely to choose DTC markets as the main outlet for fresh fruits is interesting. These results may be because shopping at DTC markets may increase the number of shopping trips to satisfy the needs of a larger family, especially when chain stores offer the possibility of one-stop shopping for larger households. Contrary to previous studies (Conner et al., 2010; Gumirakiza et al., 2014; Onianwa et al., 2005), our results suggest that smaller households were more likely to purchase fresh fruits at DTC markets $[1 \%(P<0.1)]$. Respondents in the Midwest and West were 3\% and $4 \%$ less likely to purchase fresh fruits at the DTC marketplaces $(P<0.05)$. Asian individuals were $18 \%$ less likely to buy fresh fruits at chain stores $(P<0.01)$ but $8 \%$ more likely to buy them from independent stores $(P<0.1)$ and $5 \%$ more likely to buy fresh fruits from club stores $(P<0.01)$ and DTC $(P<0.05)$ stores, respectively. These results suggest the importance of appealing to Asian shoppers during marketing campaigns because they comprise the demographic group consuming the largest amounts of fruits compared with other ethnicities (Centers for Disease Control and Prevention, 2007).

Marketplace attributes driving fruit buyers to purchase at chain stores included convenience of the marketplace $[18 \%(P<0.05)]$ and prices $[12 \%(P<0.05)]$. In contrast, market atmosphere $[18 \%(P<0.01)]$ and offering local fruits $[16 \%(P<0.05)]$ deterred shoppers from choosing chain stores. These findings suggest that supplying fruits from local farmers and improving customer service may influence customers to purchase fresh fruits at chain stores. Respondents from the South were 11\% more likely to buy fresh fruits at chain stores $(P<0.01)$, which may be explained by the abundance of fresh fruits in chain stores and the fact that they are relatively inexpensive compared with their prices in other regions and/or markets (Valpiani et al., 2015). Table 3 illustrates that those responsible for most household purchases were 7\% more likely to choose chain stores $(P<0.05)$ as the main marketplace for fresh fruits. The one-stop shop characteristic of chain stores may be driving these individuals to prefer these marketplaces as a way of reducing the number of shopping trips.

The results showed that women were $4 \%$ less likely to choose chain stores $(P<0.1)$ and $6 \%$ more likely to buy at independent stores $(P<$ $0.01)$ as their preferred marketplace for fresh fruits compared to men. This finding highlights the importance of understanding women's preferences for purchasing (or not) fresh fruits at distinct market channels, especially because women are more likely than men to make grocery purchases (Crane et al., 2019). According to Tibbits et al. (2018), women tend to prefer healthy foods; therefore, emphasizing the health and nutritional attributes of fruits can help fresh fruit retailers successfully target female buyers.

Shoppers at independent/ethnic stores were less likely to be driven by prices $[8 \%(P<0.1)]$ or market convenience $[13 \%(P<0.05)]$. Webber et al. (2010) reported that buyers who choose independent/ethnic stores are driven by specific fresh fruit attributes, including freshness and access to ethnic fruits. Despite the higher number of independent stores per county being located in the South (Cho and Volpe, 2017), our results showed that Southern buyers were $12 \%$ less likely to choose these stores for fresh fruits purchases $(P<0.01)$. One explanation may be the yearround supply of fresh fruits in the South that provides customers with many marketplace choices for fresh fruits (Valpiani et al., 2015).

\section{Conclusions}

This study proposed that before consumers choose what and how much fruit to buy, they first decide where to make the purchase. To address this decision-making process, we investigated the market attributes and consumer attitudes influencing their choice of primary marketplace 
for fresh fruits. By focusing on four categories of marketplaces, we found that most fresh fruit customers tend to prefer chain stores. Convenience and prices of fresh fruits are the main drivers of choosing large chain stores, whereas marketplace atmosphere and offering of local fruits deter consumers from choosing these market channels for fresh fruits. Our findings highlight the importance of providing a friendly atmosphere and outstanding customer service to positively influence purchasing behavior. Our results are consistent with those of the literature indicating consumer preferences for local produce, thus suggesting that buying local foods provides a sense of community involvement and may influence the presence of price premiums (Torres, 2020).

The fact that market convenience and prices were market attributes deterring customers from buying fresh fruits at independent/ethnic stores has important implications. These results suggest that managers of independent/ethnic stores should not focus their advertisement campaigns on prices; instead, they should emphasize the diversity, freshness, and selection of fresh fruits. As long as managers of these stores provide consumers with access to specialty, nutrient-dense, and ethnic fresh fruits, customers may be willing to pay a premium price for them. It is worth mentioning that several researchers have reported that market prices and availability of healthy products are major factors influencing purchases at independent stores. Yet, these studies focused mainly on small-format independent, gas station, and dollar stores (Caspi et al., 2017; Chung and Myers, 1999; Jetter and Cassady, 2006; O'Malley et al., 2013), whereas our study focused on independent, ethnic, and natural grocery stores. The fact that independent stores have an important role in the U.S. economy helping consumers to access healthy and ethnic food (Cho and Volpe, 2017) indicates the need for more research of ethnic and independent food stores offering a diversity of fresh produce.

Another important contribution of our study included the drivers and barriers to purchasing fresh fruits at local markets (i.e., DTC stores) relative to other marketplaces. The supply of local fruits, marketplace atmosphere, and access to desirable fresh fruits positively influenced customers to purchase fruits at local markets. Interestingly, the same marketplace attributes influencing customers to purchase fruits at local markets are those deterring them to purchase at chain stores. Our findings are consistent with those of Archambault et al. (2020), Kumar and Smith (2018), and Lancaster and Torres (2019), who reported that friendliness and access to local fruits entice customers to purchase at local markets. Initiatives like "know your farmer, know your food" efforts to support local farmland and local economy and local food programs at the state and community levels seem to be encouraging the demand for local foods.

Our findings suggest that local buyers are not considering price as a determinant factor when selecting their main market outlet for fresh fruits. Consistent with the results of Kumar and Smith (2018), our results showed that fresh fruit selection and diversity are major barriers for consumers buying at local markets. Increasing the offering of local foods through vendor recruitment, supporting the supply of value-added agricultural products, and extending the length of the market season for fresh fruits may help managers of local markets overcome these barriers. Overall, customers of local markets seem to place more value on knowing more about their food, where it comes from, and their health, nutritional, and safety aspects when buying fresh fruits (Torres, 2020).

Regarding consumers' attitude scales influencing the choice of marketplace, the CSF and VSF scales seem to drive consumers to purchase fresh fruits at local markets and club stores. Fruit sampling, innovative labels, and point-of-purchase marketing highlighting sweetness and variety of fruits can be effective tools for encouraging customers to purchase fresh fruits at these stores. We expect that consumers who are seeking a variety of fresh fruits may be enticed to purchase them at club stores if they have access to bundles containing different fruit types.

This study highlights the attitude factors and market attributes influencing consumers' choices of fresh fruit markets. One possible limitation of this study may be the fact that web-based surveys may have some biases but are generally accepted market research protocols that ensure accuracy and data collection speed while reducing study costs and coding errors. The size of our study sample and a robust analysis helped us address potential biases. By using an online platform, which is a convenient sampling technique, this study focused on Internet users; therefore, the sample may not reflect the general population. Future research can replicate the study by using a probabilistic sampling frame. We suggest that future research should address the values and motivations influencing fresh fruit consumers through in-depth research interviews.

\section{Literature cited}

Ailawadi, K.L., Y. Ma, and D. Grewal. 2018. The club store effect: Impact of shopping in warehouse club stores on consumers' packaged food purchases. J. Mktg. Res. 55(2):193-207, doi: 10.1509/jmr.16.0235.

Archambault, S., S. Trivette, P. Warsaw, and A. Morales. 2020. Vendor variety and market sales. J. Agr. Syst. Comm. Dev. 9(2):1-17, doi: 10.5304/jafscd.2020.092.

Arsil, P. and E. Li. 2018. Motivation-based segmentation of local food in urban cities: A decision segmentation analysis approach. Brit. Food J. 120(9):2195-2207, doi: 10.1108/BFJ-01-2018-0060.

Barrena, R., T. García, and M. Sánchez. 2017. The effect of emotions on purchase behaviour towards novel foods. An application of means-end chain methodology. Agrekon 56(2):173-190, doi: 10.1080/ 03031853.2017.1307119.

Bentley, J. 2017. U.S. trends in food availability and a dietary assessment of loss-adjusted food availability, 1970-2014. U.S. Dept. Agr., Econ. Res. Serv., Washington, DC.

Bir, C., J. Lai, N.O. Widmar, N. Thompson, J. Ellett, and C. Crosslin. 2019. There's no place like home: Inquiry into preferences for local foods. J. Food Distrib. Res. 50(1):29-45, doi: 10.22004/ ag.econ.292181.

Brunori, G., F. Galli, D. Barjolle, R. Van Broekhuizen, L. Colombo, M. Giampietro, J. Kirwan, T. Lang, E. Mathijs, D. Maye, and K. de Roest. 2016. Are local food chains more sustainable than global food chains? Considerations for assessment. Sustainability 8(5):449-476, doi: $10.3390 /$ su8050449. 
Canova, L., A. Bobbio, and A.M. Manganelli. 2020. Predicting fruit consumption: A multi-group application of the theory of planned behavior. Appetite 145:104490, doi: 10.1016/j.appet.2019.104490.

Caspi, C.E., J.E. Pelletier, L.J. Harnack, D.J. Erickson, K. Lenk, and M.N. Laska. 2017. Pricing of staple foods at supermarkets versus small food stores. Intl. J. Environ. Res. Public Health 14(8):915-927, doi: 10.3390/ijerphl4080915.

Centers for Disease Control and Prevention. 2007. Prevalence of fruits and vegetable consumption and physical activity by race/ethnicity United States, 2005. Morbidity Mortality Wkly. Rpt. 56(13):301-304. 22 Mar. 2021. <http://www.cdc.gov/mmwr/ preview/mmwrhtml/mm5613a2.htm $>$.

Chatziprodromidou, I.P., M. Bellou, G. Vantarakis, and A. Vantarakis. 2018. Viral outbreaks linked to fresh produce consumption: A systematic review. J. Appl. Microbiol. 124(4):932-942, doi: $10.1111 /$ jam.13747.

Chen, B. and S. Saghaian. 2017. Does consumers' preference for organic foods affect their store format choices? Annu. Mtg. Southern Agr. Econ. Assoc., 4-7 Feb. 2017, Mobile, AL, doi: 10.22004/ ag.econ. 252827.

Cho, C. and R. Volpe. 2017. Independent grocery stores in the changing landscape of the U.S. food retail industry. U.S. Dept. Agr., Econ. Res. Serv. ERR240. 22 Mar. 2021. <https://www.ers. usda.gov/webdocs/publications/85783/ err-240.pdf?v=0 $>$.

Christensen, J., D. Thilmany, B. Jablonski, and M. Sullins. 2017. Assessing market channel performance for Colorado fruits and vegetable producers. J. Food Distrib. Res. 48(1):61-67, doi: 10.22004/ag.econ.274569.

Chung, C. and S.L. Myers, Jr. 1999. Do the poor pay more for food? An analysis of grocery store availability and food price disparities. J. Consum. Aff. 33(2):276-296, doi: 10.1111/j.1745-6606.1999.tb00071.x.

Conner, D., K. Colasanti, R.B. Ross, and S.B. Smalley. 2010. Locally grown foods and farmers markets: Consumer attitudes and behaviors. Sustainability 2(3):742-756, doi: $10.3390 /$ su2030742.

Crane, M.M., C.C. Tangney, S.A. French, Y. Wang, and B.M. Appelhans. 2019. Gender comparison of the diet quality and sources of food purchases made by urban primary household food purchasers. J. Nutr. Educ. Behav. 51(2):199-204, doi: 10.1016/j.jneb.2018.07.016.

Curtis, K.R., K. Salisbury, R. Ward, and C. Durward. 2019. Targeting farmers' markets in Utah: Understanding fresh produce pricing. Utah State Univ. Ext., Logan.

Davidenko, O., J. Delarue, A. MarssetBaglieri, G. Fromentin, D. Tomé, N. Nadkarni, and N. Darcel. 2015. Assimilation and contrast are on the same scale of food anticipated-experienced pleasure divergence. Appetite 90:160-167, doi: 10.1016/j.appet.2015.03.006.

Ferdinand, R., R. Torres, J. Scott, I. Saeed, and R. Scribner. 2017. Incentivizing fruit and vegetable purchasers at fresh markets in lower 9th ward, New Orleans. Ethn. Dis. 27(1):287.

Figueroa-Rodríguez, K.A., M.D.C. Álvarez-Ávila, F. Hernández Castillo, R. Schwentesius Rindermann, and B. Figueroa-Sandoval. 2019. Farmers' market actors, dynamics, and attributes: A bibliometric study. Sustainability 11(3):745, doi: 10.18865/ed.27.S1.287.

Freire, T. and S. Rudkin. 2019. Healthy food diversity and supermarket interventions: Evidence from the Seacroft intervention study. Food Policy 83:125-138, doi: 10.1016/j.foodpol.2018.12.006.

Gindi, A.A., A.M. Abdullah, M.M. Ismail, and N.M. Nawi. 2018. Segmentation of fresh fruits consumers by product and store attributes at Klang Valley, Malaysia. Intl. J. Food Agr. Econ. 6(1):73-84, doi: 10.22004/ag.econ.283762.

Gumirakiza, J.D., K.R. Curtis, and R.C. Bosworth. 2014. Who attends farmers' markets and why? Understanding consumers and their motivations. Intl. Food Agribus. Manag. Rev. 17(2):65-82, doi: 10.22004/ag.econ.167905.

Hair, J., R. Tatham, R. Anderson, and W. Black. 1998. Multivariate data analysis. Prentice-Hall, London, UK.

Jetter, K.M. and D.L. Cassady. 2006. The availability and cost of healthier food alternatives. Amer. J. Prev. Med. 30(1):38-44, doi: 10.1016/j.amepre.2005.08.039.

Kenner, B. 2020. U.S. fruit imports grew by $\$ 8.9$ billion over the last decade to meet rising demand. 22 Mar. 2021. <https://www.ers.usda.gov/amber-waves/ 2020 /september/us-fruit-imports-grew-by89-billion-over-the-last-decade-to-meet-rising -demand/ $>$.

Kumar, A. and S. Smith. 2018. Understanding local food consumers: Theory of planned behavior and segmentation approach. J. Food Prod. Mktg. 24(2):196-215, doi: 10.1080/10454446.2017.1266553.

Lancaster, N.A. and A.P. Torres. 2019. Investigating the drivers of farm diversification among U.S. fruit and vegetable operations. Sustainability 11(12):3380, doi: $10.3390 /$ sul1123380.
Lenk, K.M., C.E. Caspi, L. Harnack, and M.N. Laska. 2018. Customer characteristics and shopping patterns associated with healthy and unhealthy purchases at small and non-traditional food stores. J. Commun. Healthc. 43(1):70-78, doi: 10.1007/ s10900-017-0389-5.

Lim, S.F.W., E. Rabinovich, S. Park, and M. Hwang. 2020. Shopping activity at warehouse club stores and its competitive and network density implications. Prod. Oper. Manag. 31(1):28-46, doi: 10.1111/ poms.13226.

Low, S.A., M. Bass, D. Thilmany, and M. Castillo. 2020. Local foods go downstream: Exploring the spatial factors driving U.S. food manufacturing. Appl. Econ. Perspect. Policy (early view):1-20, doi: 10.1002/aepp.13046.

Lusk, J.L. and J. McCluskey. 2018. Understanding the impacts of food consumer choice and food policy outcomes. Appl. Econ. Perspect. Policy 40(1):5-21, doi: 10.1093/aepp/ppx054.

Massaglia, S., D. Borra, C. Peano, F. Sottile, and V.M. Merlino. 2019. Consumer preference heterogeneity evaluation in fruit and vegetable purchasing decisions using the best-worst approach. Foods 8(7):266-282, doi: $10.3390 /$ foods 8070266 .

Mugera, A., M. Burton, and E. Downsborough. 2017. Consumer preference and willingness to pay for a local label attribute in Western Australian fresh and processed food products. J. Food Prod. Mktg. 23(4):452-472, doi: 10.1080/ 10454446.2015.1048019.

Nair, S.R. and S.M.R. Shams. 2020. Impact of store-attributes on food and grocery shopping behavior: Insights from an emerging market context. EuroMed J. Bus. 15(3):1-28, doi: 10.1108/EMJB-10-2019-0128.

Nakagawa, Y. and K. Kotani. 2017. Perceptive and socio-economic predictors of varied fruit and vegetable intake. Social design engineering studies SDES-201701. Koch Univ. Technol. SDES-2017-01.

O'Malley, K., J. Gustat, J. Rice, and C.C. Johnson. 2013. Feasibility of increasing access to healthy foods in neighborhood corner stores. J. Commun. Healthc. 38(4):741-749, doi: 10.1007/s10900-013-9673-1.

Onianwa, O.O., G. Wheelock, and M.N. Mojica. 2005. An analysis of the determinants of farmer-to-consumer direct-market shoppers. J. Food Distrib. Res. 36(1):130-134, doi: 10.22004/ ag.econ. 26773 .

Petit, O., F. Basso, D. Merunka, C. Spence, A.D. Cheok, and O. Oullier. 2016. Pleasure and the control of food 
intake: An embodied cognition approach to consumer self-regulation. Psychol. Mktg. 33(8):608-619, doi: 10.1002/ mar.20903.

Pollack, S.L. 2001. Consumer demand for fruit and vegetables: The U.S. example. Changing Structure Global Food Consumption Trade 6:49-54.

Printezis, I. and C. Grebitus. 2018. Marketing channels for local food. Ecol. Econ. 152:161-171, doi: 10.1016/j. ecolecon.2018.05.021.

Ritter, G. 2017. Farmers market use and perceived barriers to farmers market access among SNAP recipients in Washington State. PhD Diss., Univ. Washington, Seattle.

Roininen, K., H. Turoila, E.H. Zandstra, C. de Graaf, K. Vehkalahti, K. Stubenitsky, and D.J. Mela. 2001. Differences in health and taste attitudes and reported behaviour among Finnish, Dutch and British consumers: A cross-national validation of the health and taste attitude scales. Appetite 37(1):33-45, doi: 10.1006/ appe.2001.0414.

Saba, A., F. Sinesio, E. Moneta, C. Dinnella, M. Laureati, L. Torri, M. Peparaio, E. Saggia Civitelli, I. Endrizzi, F. Gasperi, A. Bendini, T. Gallina Toschi, S. Predieri, S. Abbà, L. Bailetti, C. Proserpio, and S. Spinelli. 2019. Measuring consumers attitudes towards health and taste and their association with food-related life-styles and preferences. Food Qual. Prefer. 73:25-37, doi: 10.1016/j.foodqual.2018.11.017.

Salisbury, K., K. Curtis, V. Pozo, and C. Durward. 2018. Is local produce really more expensive? A comparison of direct market and conventional grocery produce pricing. J. Food Distrib. Res. 49(1):13-21, doi: 10.22004/ag.econ.274599.

Schauder, S.A., M.R. Thomsen, and R.M. Nayga. 2019. The effect of the fresh fruit and vegetable program (FFVP) on fruit and vegetable consumption: An agent based modeling approach. Agr. Appl. Econ. Assn. Annu. Mtg., Atlanta, GA, 21-23 July 2019.

Schoenbachler, D.D. and G.L. Gordon. 2002. Multi-channel shopping: Understanding what drives channel choice. J.
Cons. Mktg 19(1):42-53, doi: 10.1108/ 07363760210414943.

Sirieix, L., M. Delanchy, H. Remaud, L. Zepeda, and P. Gurviez. 2013. Consumers' perceptions of individual and combined sustainable food labels: A U.K. pilot investigation. Intl. J. Consum. Stud. 37(2):143-151, doi: 10.1111/j.1470-6431.2012.01109.x.

Syeda, U.S.A. 2019. Promotion of fruit and vegetable intake through recipe card distribution and sampling at farmers' markets throughout Kentucky. MS Thesis, Univ. Kentucky, Lexington.

Tibbits, M., H. Wang, G. Soliman, S. Schram, M. Balluff, B.L. Grimm, and M. Siahpush. 2018. Demographic differences in healthy food purchases in a corner store intervention. J. Hunger Environ. Nutr. 13(4):531-539, doi: 10.1080/ 19320248.2017.1403405.

Torres, A. 2020. For young consumers farm-to-fork is not organic: A cluster analysis of university students. HortScience 55(9):1475-1481, doi: 10.21273/HORTSCI15228-20.

Torres, A., P. Langenhoven, and B.K. Behe. 2020. Characterizing the U.S. melon market. HortScience 55(6):795-803, doi: 10.21273/HORTSCI14859-20.

Torres, A.P., M.I. Marshall, C.E. Alexander, and M.S. Delgado. 2016. Are local market relationships undermining organic fruit and vegetable certification? A bivariate probit analysis. Agr. Econ. 48:1-9, doi: $10.1111 /$ agec.12326.

U.S. Department of Agriculture, Economic Research Service. 2018. Food Availability (per capita) data system: Fruit and vegetables. 22 Mar. 2021. <https:// www.ers.usda.gov/data-products/foodavailability-per-capita-data-system $>$.

U.S. Department of Agriculture, National Agricultural Statistics Service. 2016. Florida citrus statistics 2014-15. 22 Mar. 2021. $<$ https://www.nass.usda.gov/Statistics_by_ State/Florida/Publications/Citrus/Citrus_ Statistics/index.php $>$.

Uyttendaele, M., L. Jacxsens, and S. Van Boxstael. 2014. Issues surrounding the European fresh produce trade: A global perspective. Global safety of fresh produce. Woodhead, Cambridge, UK.

Valpiani, N., P. Wilde, B. Rogers, and H. Stewart. 2015. Patterns of fruit and vegetable availability and price competitiveness across four seasons are different in local food outlets and supermarkets. Public Health Nutr. 18(15):2846-2854, doi: $10.1017 /$ S1368980015000981.

van Trijp, H.C.V.M. and J.E.M. Steenkamp. 1991. Consumers' variety seeking tendency with respect to foods: Measurement and managerial implications. Eur. Res. Agr. Econ. 19(2):181-195, doi: 10.1093/erae/19.2.181.

Vega-Zamora, M., F.J. Torres-Ruiz, and M. Parras-Rosa. 2018. Key determinants of organic food consumption: The case of olive oil in Spain. HortScience 53(8):1172-1178, doi: 10.21273/HORTSCI13080-18.

Verneau, F., C.J. Griffith, E. Giampietri, A. Finco, and T. Del Giudice. 2016. Exploring consumers' behaviour towards short food supply chains. Brit. Food J. 118(3): 618-631, doi: 10.1108/BFJ-04-20150168 .

Volpe, R., A. Kuhns, and T. Jaenicke. 2017. Store formats and patterns in household grocery purchases. Econ. Res. Serv. 167:1-34, doi: 10.22004/ag. econ. 256712 .

Webber, C.B., J. Sobal, and J.S. Dollahite. 2010. Shopping for fruits and vegetables. Food and retail qualities of importance to low-income households at the grocery store. Appetite 54(2):297-303, doi: 10.1016/j. appet.2009.11.015.

Witzling, L. and B.R. Shaw. 2019. Lifestyle segmentation and political ideology: Toward understanding beliefs and behavior about local food. Appetite 13(2):106-113, doi: 10.1016/j.appet.2018.10.003.

World Health Organization. 2001. The world health report 2001 - mental health: New understanding, new hope. I June 2021. <http://www.who.int/whr/2001/ en/whr01_en.pdf $>$.

Woo, E. and Y.G. Kim. 2019. Consumer attitudes and buying behavior for green food products. Brit. Food J. 121(2):320. 